\title{
Resistance Status of Aedes aegypti to Insecticides in the Jazan Region of Saudi Arabia
}

\author{
A.A. Alsheikh ${ }^{1}$, W.S. Mohammed ${ }^{1}$, E.M. Noureldin' ${ }^{1}$, O.M. Daffalla ${ }^{1}$, \\ K.J. Shrwani ${ }^{1}$, Y.A. Hobani ${ }^{1}$, F.A. Alsheikh ${ }^{2}$, M.H. Alzahrani ${ }^{3}$ and A.A. Binsaeed ${ }^{4}$ \\ ${ }^{1}$ National Center for Vector-borne Diseases, Jazan 45142, Saudi Arabia. \\ ${ }^{2}$ College of Public Health and Tropical Medicine, Jazan University. Saudi Arabia. \\ ${ }^{3}$ Malaria Program Director, MoH- Riyadh, Saudi Arabia. \\ ${ }^{4}$ Minister Deputy for Public Health, MoH-Riyadh, Saudi Arabia.
}

http://dx.doi.org/10.13005/bbra/2018

(Received: 03 January 2016; accepted: 17 February 2016)

\begin{abstract}
The present study was designed to provide information on the susceptibility status of the adult and larvae of Aedes aegypti mosquitoes in Jazan region of Saudi Arabia. Bioassay tests were performed on adults and larvae by using WHO recommended concentrations and test kits. Adults of Ae. aegypti mosquitoes were exposed to test papers impregnated with Lambda-cyhalothrin (0.05\%), Cyfluthrin (0.15\%), Deltamethrin $(0.05 \%)$, Permethrin $(0.75 \%)$, Fenitrothion (1\%), Bendiocarb $(0.1 \%)$ and DDT $(4 \%)$ insecticides. Ae. aegypti mosquitoes were found to be susceptible only to Cyfluthrin; (mortality rate was $\mathbf{1 0 0} \%$ ), whereas variable resistances were observed from the rest of the other insecticides tested (mortality rates ranged between 93.6 and 17\%). Larvae were subjected to different concentrations of Diflubenzuron, Methoprene (IGRs) and Temephos (Organophosphate). The inhibition of adult emergence $\left(\mathrm{IE}_{50}\right.$ and $\mathrm{IE}_{95}$ ) values for the IGRs and the $\left(\mathrm{LC}_{50}\right.$ and $\left.\mathrm{LC}_{95}\right)$ for Temephos have been determined by log-probit regression analysis. The Ae.aegypti larvae were resistant to Temephos $\left(\mathrm{LC}_{50} 61.8-\mathrm{LC}_{95} 35600.1 \mathrm{mg} / \mathrm{l}\right)$ and showed high susceptibility to Methoprene than Diflubenzuron ( $\mathrm{IE}_{50} 0.49-\mathrm{IE}_{95} 10.9 \mathrm{mg} /$ l) and ( $\mathrm{IE}_{50} 0.86$ and $\left.\mathrm{IE}_{95} 93.8 \mathrm{mg} / \mathrm{l}\right)$, respectively. The larvae were more susceptible to Methoprene than Diflubenzuron by 1.8 folds.
\end{abstract}

Key words: Insecticides, resistance, Aedes aegypti, Jazan region, Saudi Arabia.

Dengue virus (DENV, Flaviviridae, Flavivirus) and Chikungunya virus (CHIKV, Togaviridae, Alphavirus) are the most significant human viral pathogen spread by the bite of an infected mosquito in most tropical regions. The annual reported cases are estimated to be 50-100 million, including 500,000 severe cases of dengue hemorrhagic fever (DHF) or dengue shock syndrome (DSS) ${ }^{1}$. DENV are the most prevalent mosquito-borne human virus worldwide. ${ }^{2}$ Globally, Aedes aegypti and Aedes albopictus are the main epidemic vectors of DENV and CHIKV. ${ }^{3,4}$

\footnotetext{
* To whom all correspondence should be addressed. E-mail: siddignoureldin@hotmail.com
}

With no vaccine or antiviral therapy currently available, disease prevention relies largely on surveillance and mosquito control by using insecticides.

Pyrethroids are still the mainstay of vector control program. The use of pyrethroid insecticides has, however, increased and that of the organochlorines and some of the more toxic organophosphate compounds has decreased in recent years.

The extensive use of insecticide in agriculture, house spraying and space spraying result in the appearing of insect that can survive and make resistance to insecticides. Appropriate monitoring of vector resistance to insecticides is an integral part of planning and evaluation of insecticide uses in control programs. 
Unfortunately, many vector control programs are threatened by the development of insecticide resistance in Ae. aegypti and Ae. Albopictus. ${ }^{5,6}$ Resistance to multiple insecticides (e.g. pyrethroids and organophosphates) has been reported in Ae. Aegypti in South America and the Caribbean. ${ }^{7,6}$ DDT resistance is now widely distributed in Ae. aegypti throughout northern Thailand and it is also resistant to the pyrethroids, permethrin and deltamethrin, in many areas. ${ }^{8,9}$

In India, Most of the studies reviewed have revealed that the adult Aedes aegypti and Aedes albopictus mosquitoes are resistant to DDT, but generally, remain susceptible to malathion, temephos, propoxur and fenitrothion. The larval stages of Aedes aegypti and Aedes albopictus have also been found to be resistant to DDT, but susceptible to larvicides, namely temephos, fenthion, and malathion. ${ }^{10}$

In South India, workers ${ }^{11}$ reported that adult Aedes aegypti and Ae. albopictus were resistant to DDT and dieldrin, but susceptible to propoxur, fenitrothion, malathion, deltamethrin, permethrin and lambda-cyhalothrin. The resistance to pyrethroids (permethrin and deltamethrin) has been developed in Ae. aegypti in most of the collected areas of Thailand. ${ }^{12}$ Workers have tested Aedes aegypti, which is the main dengue vector in Baan Suan community (Thailand) with deltamethrin, permethrin and fenitrothion. ${ }^{9}$ Their results showed that dengue mosquitoes are clearly resistant to permethrin and tolerant to deltamethrin, but were $100 \%$ susceptible to fenitrothion.

In Costa Rica, the Ae. aegypti larvae showed higher resistance levels to the organophosphate (OP) temephos and the adult were resistant to deltamethrin, but susceptible to bendiocarb, chlorpyrifos, and cypermethrin. ${ }^{13}$ In Havana city, a high resistance of Ae. aegypti larvae to temephos and fenthion was observed. ${ }^{14}$

Currently, Ae. aegypti resistance to temephos is widespread in the Americas. ${ }^{15}$ Acquired resistance by Ae. aegypti to temephos was reported in Brazil ${ }^{16-18}$, Thailand ${ }^{19}$, Bolivia and Argentina. ${ }^{20}$ Recently, incipient resistance to temephos was also reported in Ae. aegypti in Argentina. ${ }^{21}$

In Malaysia, Aedes larvae tolerance against temephos has been reported and have exhibited moderate resistance toward methoprene and low resistance toward pyriproxyfen ${ }^{22,23}$, but susceptible to diflubenzuron, cyromazine, and novaluron. ${ }^{24}$

During the past two decades, considerable progress has been made in the development of natural and synthetic compounds known as insect growth regulators (IGRs) which are capable of interfering with the process of growth, development, and metamorphosis of the target mosquito species. Two types of IGRs are available, one which inhibit the growth of larvae (Methoprene and Pyriproxyfen) due to juvenile hormone-like action and known as JH mimics or analogs and the other type of IGR compound (Diflubenzuron) which interferes with chitin production leading to moulting disturbances, resulting in the death of the insect.

In Jeddah, Saudi Arabia, the $\mathrm{LC}_{50}$ of five insecticides against Ae.aegypti larvae have been evaluated. ${ }^{25}$ The results revealed that the larvae proved to be more susceptible to Lambdacyhalothrin $(0.01 \mathrm{ppm})$ than Snap >ýPermethrin $11 \%$ + Tetramethrin 1\% + Piperonyl butoxide 11\% ?ý (0.048 ppm) and Bacilod >ýBacillus thuringiensis israelensis?ý (0.3 ppm) by about 4.8 and 30 folds, respectively. Moreover, Baycidal >ýTriflumuron 25WP?ý (0.0007 ppm) proved to be more effective against Ae. aegypti than Sumilarv >ýPyriproxyfen $0.5 \mathrm{~g}$ ?ý( $0.003 \mathrm{ppm})$ by about 4.3 folds.

In Makkah city, Saudi Arabia, it was found that the Lambdacyhalothrin was the most effective larvicide against Ae. aegypti with $\mathrm{LC}_{50}$ values of $0.007 \mathrm{ppm}$ and $0.012 \mathrm{ppm}$ for the laboratory and field strains, respectively. ${ }^{26}$

In Jazan region of Saudi Arabia, there are no available data on pesticide resistance for $A e$. aegypti against IGR and chemical insecticides used in the area. In order to implement effective and sustainable arbovirus vector control measures, there is an urgent need to determine the susceptibility of the major vector of DENV and CHIK to insecticides commonly used for mosquito control. We, therefore, examined the insecticide susceptibility for the adult and Larvae of Ae. aegypti populations in Jazan region using WHOPES-approved procedures. ${ }^{27,28}$ 


\section{MATERIALSAND METHODS}

This study was carried out in Jazan region which is located in Southwest Saudi Arabia, lies between $16^{\circ}-12$, and $18^{\circ}-25$, $N$ latitude. The Jazan region is situated in the subtropical zone and has an average monthly temperature ranging between $25.8^{\circ} \mathrm{C}$ in January to $33.4^{\circ} \mathrm{C}$ in July and average relative humidity ranges between $55 \%$ and $72.5 \%$, with an average rain of $77-56.7 \mathrm{~mm}$, (August and October), respectively. ${ }^{29}$

\section{Mosquitoes}

Aedes aegypti larvae were collected from different parts of Jazan region and brought to the insectory of the National Center for Vector-Borne Disease in Gizan city. The larvae were kept under control conditions of temperature $(25 \pm 2) \mathrm{C}^{\circ}$ and relative humidity (70-80\%) with a photo period of 12-hour darkness and 12-hour light. Pupae from water medium were transferred to mosquito rearing cages $\left(30 \mathrm{~cm}^{3}\right)$. Resulting mosquito adults were provided with $10 \%$ glucose solution supplemented with $1 \%$ vitamin B complex soaked in cotton wool.

Female mosquitoes were permitted to blood-feed on pigeons after 5 days of adult emergence. After 3 days of feeding, a piece of moist filter paper in a porcelain bowl half filled with water was introduced for egg deposition.

Eggs from filial generation $\left(\mathrm{F}_{1}\right)$ were hatched and larvae were reared in plastic trays and fed every alternate day with a powdered mixture of wheat, yeast and milk (1:1:1). Late third or early fourth instar larvae were used for larval bioassay testing. While 3-days sugar-fed adults derived from wild larvae after one generation under laboratory conditions were used for adult bioassay testing.

\section{Insecticides}

The insecticides used in this study for the larval and adult susceptibility tests were the diagnostic dosages as specified in the WHO standard methods. ${ }^{30,31}$ The insecticides were obtained from WHO Collaborating Centre in Malaysia (Vector Control Research Unit, School of Biological Sciences, Universiti Sains Malaysia, Penang). Larvae were tested against two Insect Growth Regulators (IGRs); Diflubenzuron (20 mg/ l, $4 \mathrm{mg} / \mathrm{l}, 0.8 \mathrm{mg} / \mathrm{l}, 0.16 \mathrm{mg} / \mathrm{l}$ and $0.032 \mathrm{mg} / \mathrm{l}$ ) and Methoprene (20 mg/l, 4 mg/l, 0.8 mg/l, 0.16 mg/l and $0.032 \mathrm{mg} / \mathrm{l}$ ) and organophosphate; Temephos $(0.005,0.025,0.125$ and $0.625 \mathrm{mg} / \mathrm{L})$. While adults were tested against organochlorine (DDT 4\%), organophosphate (Fenitrothion 1\%), four pyrethroids (Permethrin 0.75\%, Lambdacyhalothrin $0.05 \%$, Deltamethrin 0.05\%, Cyfluthrin 0.15\%), and Carbamate (Bendiocarb 0.1\%).

\section{Larval Bioassay}

Lots of 20 (third and fourth instar) larvae were placed in glass beakers filled with $249 \mathrm{ml}$ of distilled water and $1 \mathrm{ml}$ of each concentration of Diflubenzuron, Methoprene and Temephos. Five replicates of 20 larvae for each concentration and for control trials were used. For the Temephos, the numbers of dead larvae were recorded after 24 hours of the introduction of larvae to the beakers. While for the two IGRs, the duration of the observation period was that required for complete adult emergence in the control batches.

Percent inhibition of adult emergence (IE) was calculated and $\mathrm{IE}_{50}$ and $\mathrm{IE}_{95}$ values (effective concentration required for 50 and $95 \%$ emergence inhibition) were calculated for each of Diflubenzuron and Methoprene. Whereas, lethal concentration (LC) was calculated for Temephos $\left(\mathrm{LC}_{50}\right.$ and $\left.\mathrm{LC}_{95}\right)$.

\section{Adult bioassay}

Sugar-fed, 3-5 days old-female mosquitoes were tested. A batch of 25 adults was introduced into holding tube before being exposed to insecticide-impregnated papers. Equal numbers of control tests were also carried out by exposing mosquitoes to insecticides-free papers. The experiment was replicated four times. After the respective period of exposure, all mosquitoes were transferred to new tubes, provided with $10 \%$ sugar solution and held for 24 hours recovery period. Mortality was recorded and resistance status was determined as per WHO criteria ${ }^{28}$; a population is considered susceptible if the mortality rate is 98 $100 \%$, the possibility of resistance (80-97\%) and resistant $(<80 \%)$.

\section{Data analysis}

Data were analyzed using computerized probit analysis program (Biostat 5) to determine the $\mathrm{LC}_{50}-\mathrm{LC}_{95}$, and $\mathrm{IE}_{50}-\mathrm{IE}_{95}$ in the larval bioassay.

\section{RESULTS AND DISCUSSION}

\section{Larval susceptibility}

The efficacy of Methoprene and Diflubenzuron against Ae. aegypti Larvae is shown 
in Table 1. The result shows a high resistance of Ae. aegypti larvae to Temephos $\left(\mathrm{LC}_{50}=61.8 \mathrm{mg} / \mathrm{l}\right.$., and the best percentage mortality was obtained at the highest diagnostic dose of $0.625 \mathrm{mgll}$ was only $10 \%)$. Prolonged use of Temephos as a larvicide in Jazan region since 1986 could be one possible reason. Resistance to Temephos was detected in the region at 2003. Many authors around the world have reported resistance to Temephos in Havana ${ }^{14}$, Costa Rica $^{13}$, Brazil ${ }^{16-18}$, and Thailand ${ }^{19}$. Similar results were also recorded in Bolivia and Argentina. ${ }^{20,21}$ Contradictory, these findings are in contrast to the results reported in India ${ }^{10}$, where Ae. aegypti larvae were found susceptible to the Temephos. While in Malaysia, Ae. aegypti larvae showed to be tolerant to Temephos. ${ }^{22,23}$
The development of a new class of synthetic insect growth regulators (IGRs) Benzoylphenylureas (Chitin synthesis inhibitors) was a successful step forward towards nonhazardous and eco-safe Integrated Pest management (IPM) ${ }^{32}$

The results of the efficacy of two IGRs, Diflubenzuron and Methoprene, against Ae. aegypti larvae are shown in Table 2.

At the maximum dose of $20 \mathrm{mg} \backslash \mathrm{l}$, Methoprene and Diflubenzuron produced (100\% and $87.5 \%$ ) mortality against Ae. aegypti larvae, respectively. The $\mathrm{IE}_{50}$ of the Methoprene and Diflubenzuron were 0.49 and $0.86 \mathrm{mgl}$, respectively. This result indicates that mosquito larvae of $A e$. aegypti were more susceptible to Methoprene than Diflubenzuron by 1.8 folds.

Table 1. Efficacy of Temephos against Ae. aegypti larvae

\begin{tabular}{|c|c|c|c|c|c|}
\hline \multirow[t]{2}{*}{ Insecticide } & \multirow{2}{*}{$\begin{array}{c}\text { Concentration } \\
\text { (mg/l) }\end{array}$} & \multirow{2}{*}{$\begin{array}{l}\text { Larval Mortality } \\
\qquad(\%)\end{array}$} & \multirow{2}{*}{$\begin{array}{c}\mathrm{LC}_{50}\left(\mathrm{LC}_{95}\right) \\
(\mathrm{mg} / \mathrm{l})\end{array}$} & \multicolumn{2}{|c|}{ 95\% Confidence limit } \\
\hline & & & & $\begin{array}{c}\text { Lower } \\
\mathrm{LC}_{50}\left(\mathrm{LC}_{95}\right)\end{array}$ & $\begin{array}{c}\text { Upper } \\
\mathrm{LC}_{50}\left(\mathrm{LC}_{95}\right)\end{array}$ \\
\hline Temephos & $0.005-0.625$ & $0-10$ & $61.8(35600.1)$ & $3.2(101.9)$ & $8.2(1.31 \mathrm{E}+46)$ \\
\hline
\end{tabular}

Table 2. Efficacy of Diflubenzuron and Methoprene against Ae. aegypti larvae

\begin{tabular}{lccccc}
\hline Insecticide & $\begin{array}{c}\text { Concentration } \\
(\mathrm{mg} / \mathrm{l})\end{array}$ & $\begin{array}{c}\text { Larval Mortality } \\
(\%)\end{array}$ & $\begin{array}{c}\mathrm{LC}_{50}\left(\mathrm{LC}_{95}\right) \\
(\mathrm{mg} / \mathrm{l})\end{array}$ & $\begin{array}{c}\text { Lower } \\
\mathrm{LC}_{50}\left(\mathrm{LC}_{95}\right)\end{array}$ & $\begin{array}{c}\mathrm{Upp} \\
\mathrm{LC}_{50}\left(\mathrm{LC}_{95}\right)\end{array}$ \\
\hline Diflubenzuron & $0.032-20$ & $17-87.5$ & $0.86(93.8)$ & $0.48(30.9)$ & $1.52(583.1)$ \\
\hline Methoprene & $0.032-20$ & $18-100$ & $0.49(10.9)$ & $0.0002(1.49)$ & $81.9(7.57)$
\end{tabular}

*IE $=$ Inhibition of adult Emergence

Table 3. Mortality of adult Aedes aegypti 24 Hours after Exposure to Deltamethrin, Permethrin, Cyfluthrin, Lambda-cyhalothrin, Fenitrothion, Bendiocarb, and DDT

\begin{tabular}{lccccl}
\hline Insecticide & $\begin{array}{c}\text { Concentration } \\
(\%)\end{array}$ & $\begin{array}{c}\text { Exposure } \\
\text { period } \\
\text { (Hours) }\end{array}$ & $\begin{array}{c}\text { Number of } \\
\text { Mosquitoes } \\
\text { Tested }\end{array}$ & $\begin{array}{c}\text { Mortality } \\
(\%)\end{array}$ & $\begin{array}{l}\text { Resistance } \\
\text { status }\end{array}$ \\
\hline Deltamethrin & 0.05 & 1 & 120 & 93.3 & Possibility of resistance \\
Permethrin & 0.75 & 1 & 120 & 86.8 & Possibility of resistance \\
Cyfluthrin & 0.15 & 1 & 120 & 100 & Susceptible \\
Lambda-cyhalothrin & 0.05 & 1 & 120 & 76.5 & Resistant \\
DDT & 4 & 1 & 120 & 56.3 & Resistant \\
Fenitrothion & 1 & 1 & 100 & 93.6 & Possibility of resistance \\
Bendiocarb & 0.1 & 1 & 100 & 17 & Resistant \\
\hline
\end{tabular}


The efficacy of Diflubenzuron against Ae. aegypti in this study is in contradiction with that of Nusrat et al. ${ }^{33}$ and Seccacini et al. ${ }^{34}$ who noted that the Diflubenzuron was highly effective for inhibition of adult emergence, and (100\%) adult emergence inhibition was observed in the presence of $0.1 \mathrm{ppm}$.

With low concentration (0.032 $\mathrm{mg} / \mathrm{l})$, Methoprene was found to be less effective in reducing the emergence of adult Ae. aegypti mosquito (Table 2), a result that matches the findings of Nayar et al. ${ }^{35}$

The $\mathrm{IE}_{50}-\mathrm{IE}_{95}$ range $(0.86-93.8 \mathrm{mgl})$ post exposure (Table 2 ) against Diflubenzuron indicated less effect at larval stages as compared with Methoprene (0.49 - $10.9 \mathrm{mg} \backslash \mathrm{l})$. This finding of the effectiveness of the Methoprene against Ae. aegypti larvae in Jazan region is more relevant to the results obtained by other workers. ${ }^{34,36-40}$

In Malaysia, it was found that the larvae of Ae. aegypti exhibited moderate resistance toward Methoprene and low resistance toward Pyriproxyfen, with resistance ratios of 12.7 and 1.4, respectively, but susceptibility to Diflubenzuron. ${ }^{24}$

In this study, comparing the larvicidal activity of Methoprene with Diflubenzuron and Temephos (Table 1 and 2) it can be inferred that Methoprene is more effective against Ae. aegypti and can be used as an alternative larvicide in the areas where the low efficacy of Diflubenzuron and high resistance to organophosphate compounds have been detected.

\section{Adult susceptibility}

The mortality of Aedes aegypti 24 hours after exposure to Deltamethrin, Permethrin, Cyfluthrin, Lambda-cyhalothrin, and DDT is presented in Table 3.

The adult susceptibility from the different parts of Jazan revealed that the mosquitoes were susceptible to Cyfluthrin (100\% mortality) and having a possibility of resistance to each of Fenitrothion, Deltamethrin, and Permethrin (93.6\%, $93.3 \%$, and $86.8 \%$, respectively). While, mosquitoes were resistant to Lambda-cyhalothrin (76.5\%) and DDT (56.3\%), as well as, they were highly resistant to Bendiocarb (17\%).

It can be seen that Ae. aegypti showed the possibility of resistance to Deltamethrin and Permethrin (mortality 93.3\%, 86.8\%, respectively) in Jazan region. This result is in accordance with the findings of other authors in Thailand who reported the resistance of Ae. aegypti to Permethrin and Deltamethrin ${ }^{12}$. Whereas, the possibility of resistance of Ae. aegypti to the two insecticides is contradicted with the work of authors in India who found that adults Aedes aegypti and Ae. albopictus were susceptible to Deltamethrin and Permethrin ${ }^{11}$.

Deltamethrin and Permethrin could have resulted from cross-resistance with DDT. Moreover, the use of household aerosol insecticides where the main active ingredient is Permethrin might have contributed to the resistance of the species.

The development of high resistance against Bendiocarb (17\%) and possibility of resistance against Fenitrothion (93.6\%) could be due to the selection for resistance in the mosquitoes resulting from municipal and agricultural applications. ${ }^{41}$ In addition, Fenitrothion has been used in the region as an interdomicilary residual spray between 1987 and 1994. However, the high resistance to Bendiocarb in our study is contrasting the findings of workers in Costa Rica, where Ae. aegypti was susceptible to it. ${ }^{13}$

In this study, Ae. aegypti mosquitoes showed resistance to Lambda-cyhalothrin and DDT, a result which was similarly obtained by other authors in India ${ }^{11}$ with the exception only to the susceptibility of Ae. aegypti to Lambdacyhalothrin. Conversely, when taking the $\mathrm{LC}_{50}$ into consideration, workers in Jeddah found the larvae of Ae. aegypti to be susceptible to Lambdacyhalothrin at a concentration of 0.01 ppm. ${ }^{25}$ In Jazan region, the mosquito larvae have exhibited resistance to DDT as early as 1987 where the insecticide has long been used to control the vector of malaria.

Our findings show the appearance of resistance to multiple insecticides (e.g. Pyrethroids and Organochlorines) in Ae. aegypti. The same findings of multiple resistances between Pyrethroids and another group (Organophosphates) have been reported in SouthEast Asia ${ }^{12}$, South America and the Caribbean. ${ }^{6,7}$

The extensively successive use of Pyrethroids (Lambda-cyhalothrin, Deltamethrin, and Permethrin) in the region to control Malaria, Dengue and Rift valley mosquito vectors by the Ministries of Health, Municipality and Agriculture, respectively, might have been contributed to 
accelerating the resistance to this group of insecticides.

This study revealed the effectiveness of Cyfluthrin against the adults of Ae. aegypti (100\% mortality). This result may be attributed to the fact that Cyfluthrin is newly introduced to the region.

The resistance of Ae. aegypti against the tested insecticides decreased in the order of:

Bendiocarb $>$ DDT $>$ Lambda-cyhalothrin $>$ Permethrin $>$ Deltamethrin $>$ Fenitrothion $>$ Cyfluthrin.

\section{CONCLUSION}

In this study, Cyfluthrin was found to be the only effective Pyrethroid used in Jazan region against the adult of Ae. aegypti. Methoprene on other hand proved to be an effective IGR against the larvae of Ae. aegypti in the region.

These results suggest that continuous resistance monitoring should be conducted regularly to identify the efficacy of compounds for dengue control. Well-managed rotation of the effective insecticides, community awareness and participation, and public health campaigns to reduce larval breeding sites are recommended strategies to control dengue infections.

Moreover, the use of IGRs should be considered as an alternative when the larvae of Ae. aegypti develop resistance to conventional insecticides.

Further studies should be carried out to provide more information about resistance status and to identify the resistance mechanism by PCR test in order to confirm and supplement the bioassay results.

\section{REFERENCES}

1. WHO Dengue: guidelines for diagnosis, treatment, prevention and control- New edition. WHO/HTM/NTD/DEN/2009.1

2. Gubler, DJ. Epidemic dengue/dengue hemorrhagic fever as a public health, social and economic problem in the 21st century. Trends Microbiol. 2002; 10: 100-103. doi:10.1016/ S0966-842X(01)02288-0.

3. Peyrefitte C., D Rousset, B Pastorino, R Pouillot, M Bessaud, F Tock, H Mansaray, O Merle, A Pascual, C Paupy, A Vessiere, P Imbert, P Tchendjou, JP Durand, $\mathrm{H}$ Tolou, M
Grandadam. Chikungunya virus, Cameroon. Emerg Infect Dis. 2007; 13: 768-771.

4. Kow, CY., Koon, LL. \& Pang, FY. Detection of dengue viruses in field caught male Aedes aegypti and Aedes albopictus (Diptera: Culicidae) in Singapore by type-specific PCR. J Med Entomol. 2001; 38: 475-479. Doi: 10.1603/ 0022- 2585-38.4.475.

5. Yaicharoen, R., Kiatfuengfoo, R., Chaeronviriyaphap, T., \& Rongnoparut, P. Characterization of deltamethrin, resistance in field populations of Aedes aegyptiin Thailand. $J$ Vect Ecol. 2005; 30: 144-150.

6. Marcombe, S., Carron, A., Darriet, F., Etienne, M., Agnew, P., Tolosa, M., MM Yp- Tcha, Lagneau, C., Yébakima, A. \& Corbel, V. Reduced Efficacy of Pyrethroid Space Sprays for Dengue Control in an Area of Martinique with Pyrethroid Resistance. Am J Trop Med Hyg. 2009; 80: 745751.

7. Rawlins, SC., Martinez, R., Wiltshire, S \& Legall, G. A comparison of surveillance systems for the dengue vector Aedes aegypti in Port of Spain, Trinidad. J Am Mosq Control Assoc. 1998; 14: 131-136.

8. Somboon P, Prapanthadara L and Suwonkerd W. Insecticide susceptibility test of Anopheles minimus s.1., Aedes aegypti, Aedes albopictus, and Culex quinquefasciatus in northern Thailand. Southeast Asian J Trop Med Public Health. 2003; 34(1): 87-93.

9. Sathantriphop S, Paeporn P\&, Supaphathom $\mathrm{K}$. Detection of insecticides resistance status in Culex quinquefasciatus and Aedes aegypti to four major groups of insecticides. Tropical Biomedicine. 2006; 23(1):97-101.

10. Singh, RK., Haq, S., Gaurav Kumar, Mittal, PK. and Dhiman, RC. Insecticide susceptibility status of dengue vectors Aedes aegypti and Aedes albopictus in India: a review Dengue Bulletin 2013; 37:177.

11. Sharma SN, Saxena VK and Lal S. Study on susceptibility status in aquatic and adult stages of Aedes aegypti and Ae. albopictus against insecticides at international airports of south India. The Journal of Communicable Diseases. 2004; 36(3):177-81.

12. Jirakanjanakit, N. Rongnoparut, P., Saengtharatip, S., Chareonviriyaphap, T., Duchon, S., Bellec, C., Yoksan, S. Insecticide susceptible/resistance status in Aedes (Stegomyia) aegypti and Aedes (Stegomyia) albopictus (Diptera: Culicidae) in Thailand during 2003-2005. J Econ Entomol. 100, 545-550. Doi: 10.1603/0022 0493 (2007)100[545: IRSIAS] 2.0.CO; 2. 
13. Bisset JA, Marín R, Rodríguez MM, Severson DW, Ricardo Y, French L, Díaz M, Pérez O. Insecticide resistance in two Aedes aegypti (Diptera: Culicidae) strains from Costa Rica. $J$ Med Entomol. 2013; 50(2):352-61.

14. Magdalena Rodríguez M, Bisset JA, Fernández $\mathrm{D}$, Omayda P. Resistance to insecticides in larvae and adults of Aedes aegypti, Havana City: prevalence of A4 esterasa associated with resistance to temephos. Rev Cubana Med Trop. 2004; 56(1):54-60.

15. WHO Vector resistance to pesticides. $15^{\text {th }}$ report of the WHO Expert Committee on Vector Biology and Control. Geneva, Switzerland: World Health Organization.1992

16. Lima JBP, Pereira da Cunha M, Silva RCS, Galardo AKR, Soares SS, Braga IA, Ramos RP, Valle D. Resistance of Aedes aegypti to organophosphates in several municipalities in the states of Rio de Janeiro and Espirito Santo, Brazil. Am J Trop Med Hyg, 2003; 68: 329333.

17. Macoris MLG, Andrighetti MTM, Takaku L, Glasser CM, Garbeloto VC, Bracco JC. Resistance of Aedes aegypti from the state of S. Paulo, Brazil, to organophosphates insecticides. Mem Inst Oswaldo Cruz, 2003; 98:703-708.

18. Braga IA, Lima JBP, Soares SS, Valle D. Aedes aegypti resistance to temephos during 2001 in several municipalities in the states of Rio de Janeiro, Sergipe and Alagoas, Brazil. Mem Inst Oswaldo Cruz, 2004; 99: 199-203.

19. Jirakanjanakit, N., Saengtharatip, S., Rongnoparut, P., Duchon, S., Bellec, C., Yoksan, S. Trend of Temephos resistance in Aedes (Stegomyia) mosquitoes in Thailand during 2003-2005. Environ Entomol. 36: 506-511. Doi: 10. 1603/0046-225X (2007)36[506: TOTRIA] 2.0.CO; 2.

20. Biber P, Rondan-Dueñas J, Dudueña AF, Gardenal C, Almiron W. Laboratory evaluation of susceptibility of natural subpopulations of Aedes aegypti larvae to temephos. J Am Mosq Control Assoc, 2006; 22: 408-411.

21. Seccacini E, Lucý'a A, Licastro S, Zerba E \& Masuh H. Resistencia a temefos de Aedes aegypti (Diptera: Culicidae) en localidades del norte argentino. 5th Regional Mosquito Meeting (Argentina). Rev Biologia Acuatica, 2007; 23:48.

22. Lee, H.-L., and W. Lime. A re-evaluation of the susceptibility of field collected Aedes (Stegomyia) aegypti (Linnaeus) larvae to temephos in Malaysia. Mosq. Borne Dis. Bull. 1989; 4: 91-95.

23. Chen, C.-D.,W. A. Nazni,H.-L. Lee, andM. Sofian-Azirun. Susceptibility of Aedes aegypti and Aedes albopictus to temephos in four sites in Kuala Lumpur City Center and Selangor State, Malaysia. Trop. Biomed. 2005; 22: 207-216.

24. Lau KW, Chen CD, Lee HL, Norma-Rashid Y, Sofian-Azirun M. Evaluation of insect growth regulators against field-collected Aedes aegypti and Aedes albopictus (Diptera: Culicidae) from Malaysia. Journal of medical entomology. 2015; 52(2):199-206.

25. Al-Ghamdi K, Z.I. Al-Fifi, M.S.Saleh, H.A. AlQhtani and J.A. Mahyoub. Insecticide susceptibility of Ae.aegypti, the vector of dengue fever, in Jeddah governorate, Saudi Arabia. Biosciences,Biotechnology Research Asia, 2008; 5(2): 501-506.

26. Al Thbiani Aziz, Hamady Dieng, Ahmad Abu Hassan, Tomomitsu Satho, Fumio Miake, Md Rawi Che Salmah, Sazaly AbuBakar. Insecticide susceptibility of the dengue vector Ae.aegypti ( Diptera: culicidae) in Makkah City,Saudi Arabia. Asian Pacific Journal of Tropical Disease 2011; 1(2):94-99.

27. WHO Guidelines for laboratory and field testing of mosquito larvicides. (Document WHO/CDS/ WHOPES/GCDPP/13, Geneva, Switzerland, World Health Organization. 2005

28. WHO Guidelines for testing mosquito adulticides for indoor residual spraying and treatment of mosquito nets. (Document WHO/ CDS/NTD/ WHOPES/GCDPP/3, Geneva, Switzerland, World Health Organization. 2006

29. Adel A. Al-sheikh. Larval habitat, Ecology, Seasonal abundance and vectorial role in malaria transmission of An. arabiensis in Jazan region of Saudi Arabia. Journal of the Egyptian Society of Parasitology, 2011; 41(3): 615-634.

30. WHO Instructions for determining the susceptibility or resistance of mosquito larvae to insecticides. Geneva, World Health Organization.1981

31. WHO Instructions for determining the susceptibility or resistance of adult mosquitoes to organochlorine, organophosphate and carbamate insecticides - diagnostic test. Geneva, World Health Organization. 1981

32. Tunaz, H. and N. Uygun. Insect growth regulators for insect pest control. Turk.J.Agri.for. 2004; 28:377-387.

33. Nusrat Jahan, Jaweeria Razaq and Ayesha Jan. Laboratory Evaluation of Chitin Synthesis Inhibitors (Diflubenzuron and Buprofezin) Against Aedes aegypti Larvae from Lahore, Pakistan. Pakistan J. Zool., 2011; 43(6): 10791084.

34. Seccacini, E. Alejandro Lucia, Laura Harburguer, Eduardo Zerba, Susana Licastro and Hector 
Masuh. Effectiveness of Pyriproxyfen and Diflubenzuron Formulations as Larvicides Against Aedes aegypti. Journal of the American Mosquito Control Association, 2008; 24(3):398403.

35. Nayar, J.K., Ali, A. and Zaim, M. Effectiveness and residual activity comparison of granular formulations of insect growth regulators Priproxifen and s-Methoprene against Florida mosquitoes in laboratory and outdoor conditions. J. Am. Mosq. Contr. Assoc., 2002; 18: 196-201.

36. Braga IA, Mello CB, Montella IR, Lima JB, Martins Ade J, Medeiros PF \& Valle D. Effectiveness of methoprene, an insect growth regulator, against temephos-resistant Aedes aegypti populations from different Brazilian localities, under laboratory conditions. $\mathrm{J} \mathrm{Med}$ Entomol. 2005; 42(5):830-7.

37. Garg, R.C. and W.A. Donahue. Pharmacologic profile of methoprene, an insect growth regulator, in cattle, dogs, and cats. J. Am. Vet. Med.
Assoc.1989; 194: 410-412. Hyg 68:329-333.

38. Sulaiman Sallehudin; Siti Hajar, A. S.; Hidayatulfathi Othman. Residual efficacy of insect growth regulators pyriproxyfen, triflumuron and smethoprene against Aedes aegypti (L.) in plastic containers in the field. Tropical Biomedicine, 2004; 21(1): 97-100. 9 ref. 211 97-100.

39. Silva, Juliana Junquerira, Mendes and Júlio. Susceptibility of Aedes aegypti to the insect growth regulators diflubenzuron and methoprene in Uberlandia, State of Minas Gerais. Sociedade Brasileria de Medicina Tropical-SBMT. 1/12/ 2007.

40. Chen, C.D., Seleena, B., Chiang, Y.F. and Lee, H.L. Field evaluation of the bioefficacy of diflubenzuron (Dimilin ${ }^{\circledR}$ ) against containerbreeding Aedes sp. mosquitoes. Tropical Biomedicine, 2008; 25(1): 80-86 .

41. Lines JD. Do agricultural insecticides select for insecticide resistance in mosquitoes? A look at the evidence. Parasitol Today. 1988; 4(7):S1720. 